\title{
Comparative study of various methods of fetal weight estimation at term pregnancy in a tertiary hospital in Kanchipuram, Tamil Nadu, India
}

\author{
Parvathavarthini K.*, Santhanalakshmi C., Geetha Prasad
}

Department of Obstetrics and Gynecology, Karpaga Vinayakar Institute of Medical Sciences, Chinna Kolambakkam, Kanchipuram, Tamil Nadu, India

Received: 14 February 2018

Accepted: 09 March 2018

\section{*Correspondence:}

Dr. Parvathavarthini K.,

E-mail: parvvi@gmail.com

Copyright: (c) the author(s), publisher and licensee Medip Academy. This is an open-access article distributed under the terms of the Creative Commons Attribution Non-Commercial License, which permits unrestricted non-commercial use, distribution, and reproduction in any medium, provided the original work is properly cited.

\section{ABSTRACT}

Background: Prediction of fetal weight is one of the methods towards effective management of pregnancy and delivery. Ultrasonography is the standard method to monitor the weight, but in the absence of such facility it becomes difficult particularly in the primary care setting. Clinical methods can be considered as an option and this requires selection of the valid method in deriving the fetal weight. In the present study, an effort is made to compare two different clinical methods and USG and relate to the actual weight of the baby at birth.

Methods: One hundred pregnant women satisfying the criteria, consenting for the study were recruited. Both USG and clinical methods were done and estimated the fetal weight. Weight of the baby at birth was measured.

Results: All the three methods had significant relationship with the baby weight. Results indicated that estimation of fetal weight by Dare's formula could predict $69 \%$ of the cases correctly followed by Johnson's method which could predict $61 \%$ of the cases correctly. USG predicted $67 \%$ of the cases correctly. Percentage error was least with USG and the standard deviation of error was lower with Dare's formula.

Conclusions: It can be concluded that Dare's formula of clinical methods can be a potential option to be promoted in predicting the fetal weight in the absence of USG facilities. Training in this method is very important and can be an integral part in managing pregnancy during delivery in primary care setting.

Keywords: Clinical techniques, Fetal weight at term pregnancy, Prediction, Ultrasonography

\section{INTRODUCTION}

Information of fetal weight is vital in management of labour and delivery. Birth weight of infant is the important determinant of new born survival. Extremes of birth weight are both associated with increased risk of neonatal morbidity during labour and postpartum period. The potential complications of large fetus associated with vaginal delivery include shoulder dystocia, brachial plexus injury, bone injuries, and intrapartum asphyxia, while the maternal risks include birth canal and pelvic floor injuries, increased rate of operative vaginal and caesarean deliveries, and postpartum haemorrhage. Categorization of fetus into small or large for gestation age will help in timely obstetrics management. ${ }^{1-3}$ Hence accurate measurement of birth weight is important in managing labour and on deciding the mode of delivery. Also, estimation of fetal weight play a vital role in the management of diabetic pregnancy, vaginal delivery after caesarean section (VBAC) and intrapartum management of fetus with breech presentation. ${ }^{1}$ Fetal weight can be estimated by clinical and ultrasound methods. Finding a 
simple and effective method in estimating fetal weight will be useful for the birth attendants and paramedical staff working in rural areas to decide on referral of cases to higher centres. ${ }^{4}$ This is true in a developing countries like India, where USG facilities are mostly not available and an equivalent alternative method is to be found for estimating fetal weight which will help in timely referral from periphery. A number of studies have been carried out, on the estimation of fetal weight at term pregnancy. . $^{-}$ 12 However, large sample sized studies are required to recommend the same at peripheral centres with intensive training of health staff.

The present study aimed at comparing the different methods of estimating fetal weight involving 100 subjects to identify the valid method.

\section{METHODS}

It was a prospective analytical study conducted in the department of obstetrics and gynecology, Karpaga Vinayagar Medical College, Madurantakam between November 2017 to January 2018. This study was not an interventional study and has the approval of Institutional human ethics committee.

All the healthy women at the gestational period of $37-42$ weeks who reported to the out-patient department of Obstetrics and Gynaecology during the study period were considered for the study. A total of 100 women were selected at random for recruitment. The inclusion criteria for the study included singleton pregnancy, cephalic presentation, normal liquor and reliable dates. Women reporting with multiple pregnancy, mal-presentation, oligohydramnios, polyhydramnios, fibroid complicating pregnancy, adnexal mass complicating pregnancy, obvious uterine anomaly, obese mother BMI >30, preterm/posterm, ruptured membrane, intrauterine death, fetal anomalies and patients who deliver one week after ultrasonographic and clinical estimation of fetal weight were excluded from the study. Total of 100 subjects were selected against a minimum sample of 75 estimated based on the expected difference between the means of 100 grams, 0.05 two tailed level of significance, $80 \%$ power, standard deviation of 0.361 in clinical cases and 0.058 in USG and 0.817 common correlation co-efficient value.

All the relevant history and examination of the selected patients were done using the proforma after obtaining consent. Both clinical and ultrasonographic methods were used to assess the fetal weight. The interval between estimation of fetal weight and delivery was within 7 days. Different clinical methods used in the study were Dare's formula $^{13}$ (symphysiofundal height $(\mathrm{SFH}) \times$ abdominal girth $(A G))$ and Johnson's formula ${ }^{14}$ ((SFH-X) x 155) where $X$ is 12 if the vertex is above 0 station and $X$ is 11 if station is below $0 . \mathrm{SFH}$ is measured using an inch tape from the highest point in the uterine fundus after correcting the rotation to the midpoint of upper border of pubic symphysis. AG is measured using the inch tape at the level of umbilicus. The patient was subsequently subjected to ultrasonographic examination of fetal weight. Handlock's formula was used to estimate the fetal weight on the basis of biparietal diameter, head circumference, abdominal circumference, and femoral length. After delivery the birth weight was taken within 30 minutes of delivery. If the delivery does not occur within one week from the date of evaluation all the measurement was repeated. After knowing the actual birth weight, a comparative evaluation of all the methods were done using appropriate statistical method.

The values estimated using all the three formulae were compared using regression analysis, chi-square test for proportion and student t-test.

\section{RESULTS}

Out of 100 patients 64 underwent normal spontaneous vaginal delivery, 32 patients required caesarean section and 4 patients had instrumental delivery. While 51 patients were primigravida, 49 were multigravida.

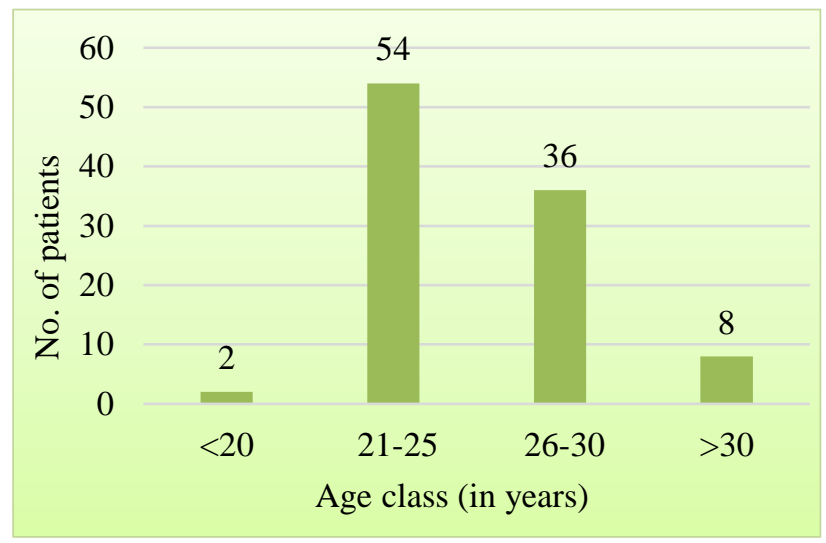

Figure 1: Distribution of patients by age.

Distribution of study subjects in relation to age showed that majority of them were in the age class $21-25$ (54\%) followed by $26-30$ years (36\%) (Figure 1). The number of subjects examined at 37 weeks term pregnancy was 31,9 were at 38 weeks, 44 were at 39 and 16 were at 40 weeks (Figure 2). All the 100 women delivered babies with $62 \%$ boys and $38 \%$ girls. The weight of the baby was not significantly associated with mother's weight (Figure 3).

The mean value of fetal weight estimated by USG was $3175.1 \pm 483.3 \mathrm{gm}$ and the actual baby weight at birth was $2984.21 \pm 490.3 \mathrm{gm}$. Correlation co-efficient was highest (0.69) with Dare's method, followed by USG (0.66) and Johnson's method (0.61). Corresponding standard error with the respective method was $357.7,360.7$ and $389.8 \mathrm{gm}$. The percentage of cases that could be correctly predicted by USG was 66.9. The mean value of fetal weight derived by Dare's formula from clinical method was $3363.2 \pm 487.8 \mathrm{gm}$ and $68.7 \%$ of cases could be correctly predicted by this method. 


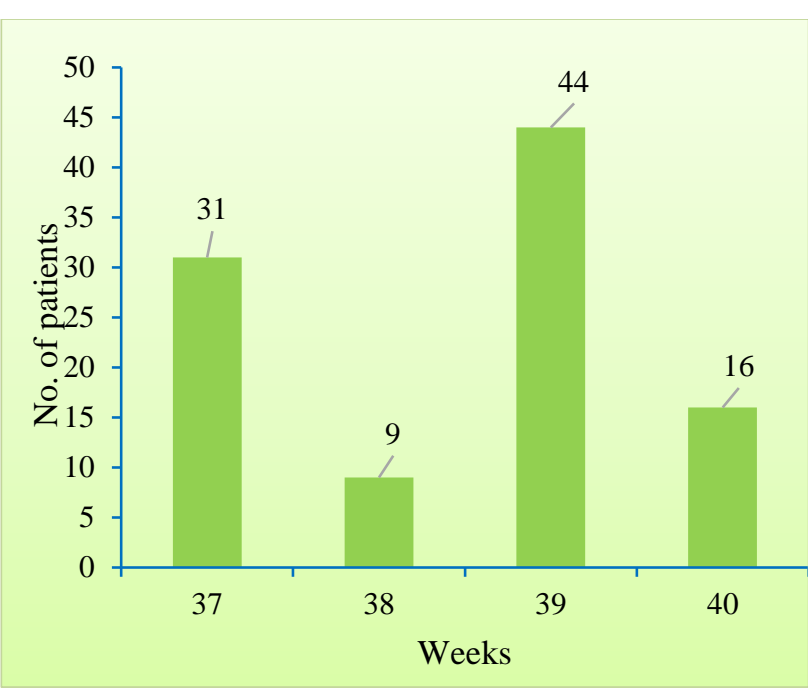

Figure 2: Distribution of patients in relation to term pregnancy (weeks).

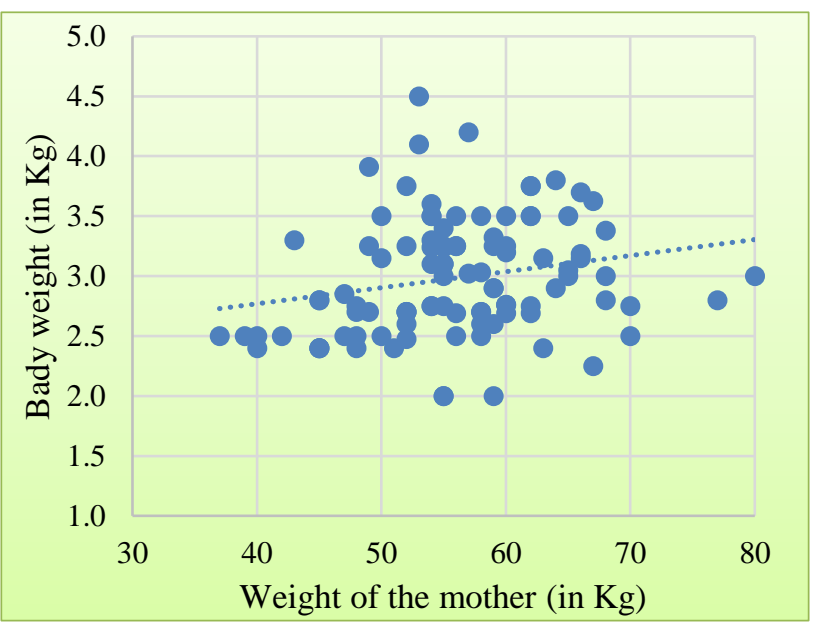

Figure 3: Relationship between weight of the mother and baby.

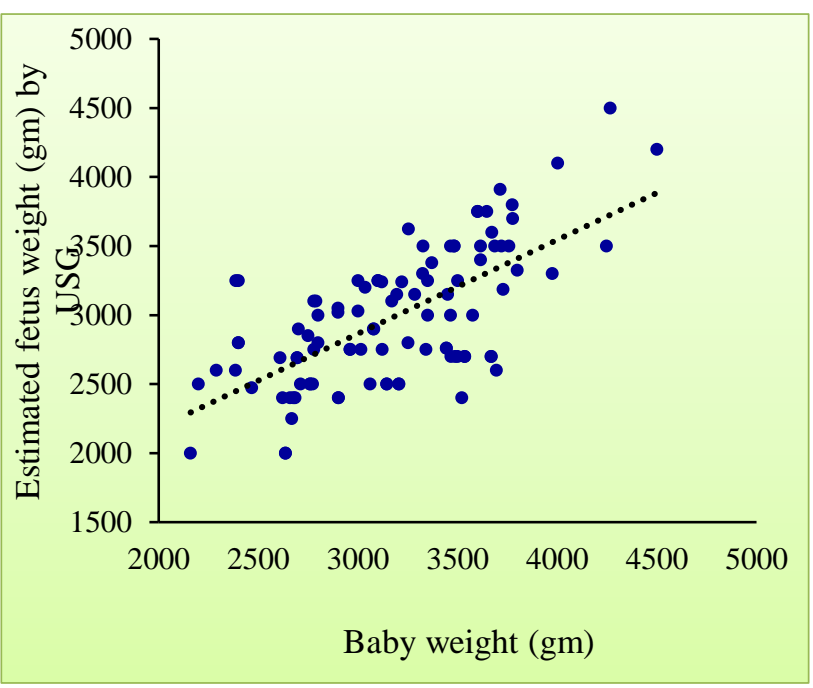

Figure 4: Relation between estimated fetus weight by USG and baby weight at birth.

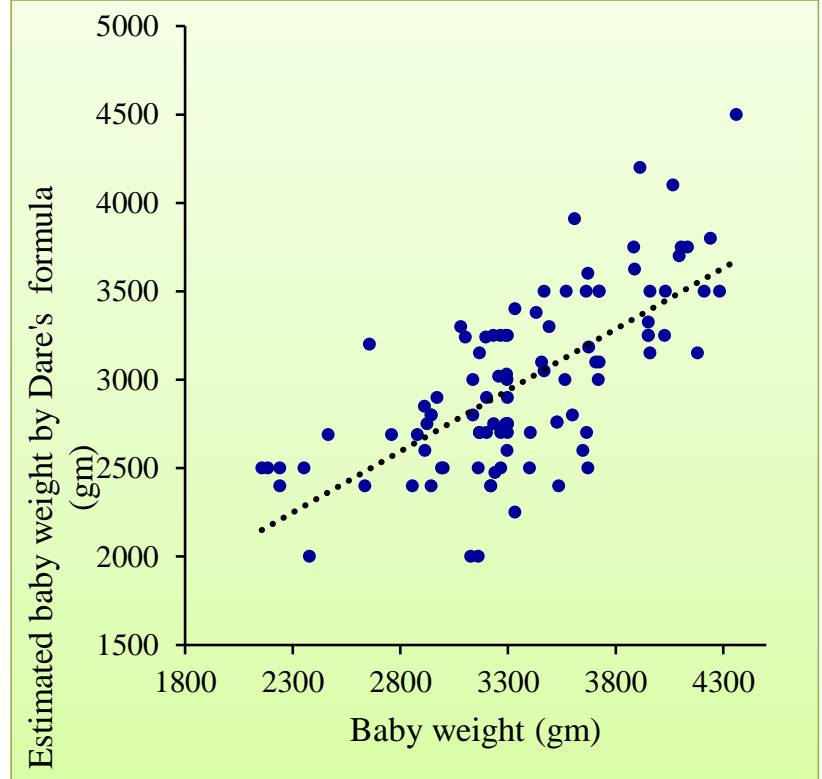

Figure 5: Relation between estimated fetus weight by Dare's formula and baby weight at birth.

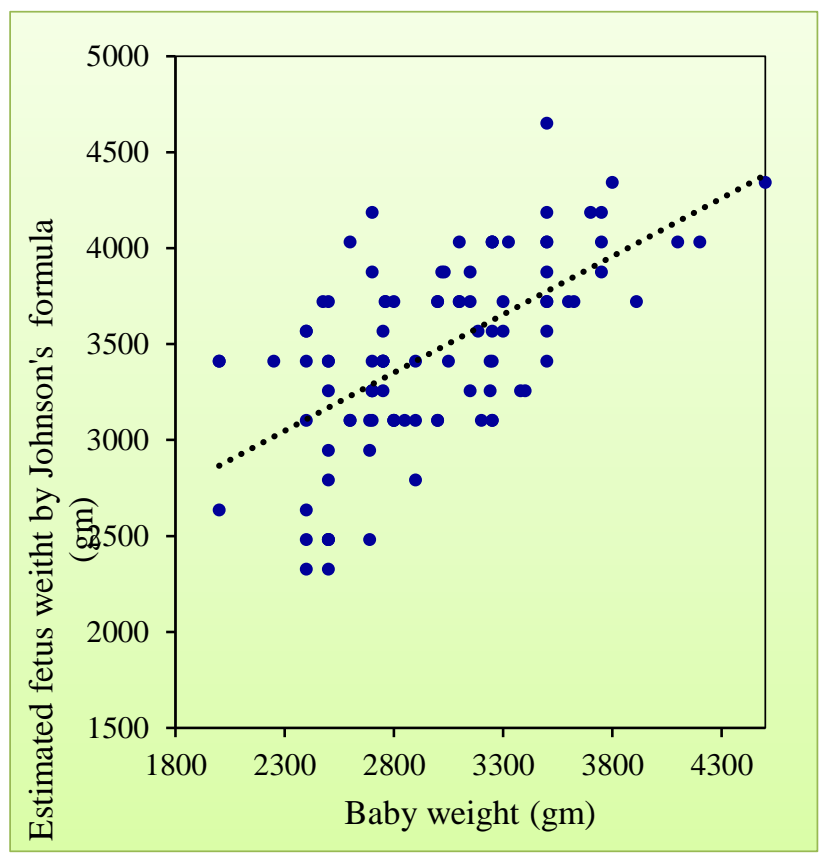

Figure 6: Relation between estimated fetus weight by Johnson's formula and baby weight at birth.

There was a significant relationship between the predicted values of USG, Dare's method and Johnson's method and the actual baby weight (Figure 4-6).

The mean weight of fetal weight by Johnson's formula was $3462.7 \pm 485.8 \mathrm{gm}$ (Table 1). This method could predict $61.2 \%$ of the cases correctly. Comparison of correct detectability between the methods showed that Dare's formula could predict the cases correctly by around $2 \%$ when compared to USG method and $10 \%$ more when compared to Johnson's method. 
The estimated fetal weight was 1.06 times of actual baby weight by USG while it was 1.12 times by Dare's method and 1.16 times by Johnson's method. The estimated values of all the three methods were close to the actual baby weight. Average absolute error (Table 2) observed by USG was $190.8 \mathrm{gm}$. It was relatively higher by clinical method; (Dare's formula: 379.0gm and Johnson's method: $478.5 \mathrm{gm})$.

Table 1: Predicted baby weight by different methods in relation to weight grade and gender.

\begin{tabular}{|llllllllllll|}
\hline Range & Number & $\begin{array}{l}\text { Mean } \\
\text { weight }\end{array}$ & Male & Female & Total & Male & Female & Total & Male & Female & Total \\
\hline$<2.5$ & 12 & 2293.8 & 2726.2 & 2695.8 & 2711.0 & 2985.8 & 2996.2 & 2991.0 & 3229.2 & 3048.3 & 3138.8 \\
\hline $2.5-4.0$ & 85 & 3036.4 & 3116.9 & 3367.7 & 3202.5 & 3318.3 & 3526.3 & 3389.3 & 3401.7 & 3645.2 & 3484.8 \\
\hline$>4$ & 3 & 4266.7 & NA & 4255.3 & 4255.3 & NA & 4113.3 & 4113.3 & NA & 4133.3 & 4133.3 \\
\hline
\end{tabular}

Table 2: Absolute error of predicted values against the actual baby weight by different methods in relation to weight grades.

\begin{tabular}{|llllll|}
\hline Baby weight & \multicolumn{4}{c|}{ Predicted baby weight by } \\
\hline $\begin{array}{l}\text { Range } \\
\text { (Kg) }\end{array}$ & No. & $\begin{array}{l}\text { Mean } \\
\text { weight } \\
\text { (gm) }\end{array}$ & USG & $\begin{array}{l}\text { Dare's } \\
\text { method }\end{array}$ & $\begin{array}{l}\text { Johnson's } \\
\text { method }\end{array}$ \\
\hline$<2.5$ & 12 & 2293.8 & 417.3 & 697.3 & 845.0 \\
\hline $2.5-4.0$ & 85 & 3036.4 & 166.1 & 352.9 & 448.3 \\
\hline$>4$ & 3 & 4266.7 & -11.3 & -153.3 & -133.3 \\
\hline Total & 100 & 2984.2 & 190.9 & 379.0 & 478.5 \\
\hline
\end{tabular}

The percentage error was $6.4 \%$ by USG and it was higher by Dare's method $(12.5 \%)$ as well as Johnson's method $(16.0 \%)$. Maximum error in USG was 1120 while it was 1172 by Dare's method and 1485 by Johnson's method. The standard deviation of errors was 396.4, 382.6 and 430.9 by USG, Dare's and Johnson's method. The percentage error was relatively higher in Johnson's method, followed by Dare's method and it was least by
USG (Table 3). Among the baby weight categories, it was optimal with normal category. Maximum error was in underweight category.

USG predicted excess of actual baby weight in $64 \%$ of the cases, while it was $83 \%$ by Dare's and Johnson's method. The remaining were less of actual baby weight in the methods used in the present study. Underestimation of fetal weight was more with USG when compared to both the clinical methods.

Table 3: Percentage error of predicted value against the actual baby weight by different methods.

\begin{tabular}{|llll|}
\hline $\begin{array}{l}\text { Baby weight } \\
(\mathrm{Kg})\end{array}$ & USG & $\begin{array}{l}\text { Dare's } \\
\text { method }\end{array}$ & $\begin{array}{l}\text { Johnson's } \\
\text { method }\end{array}$ \\
\hline$<2.5$ & 20.02 & 30.35 & 35.51 \\
\hline $2.5-4.0$ & 5.47 & 11.62 & 14.77 \\
\hline$>4$ & -0.27 & -3.59 & -3.13 \\
\hline Overall & 6.40 & 12.70 & 16.03 \\
\hline
\end{tabular}

Table 4: Number of cases showing under and over estimates by percentage in different methods.

\begin{tabular}{|c|c|c|c|c|c|c|}
\hline \multirow[b]{2}{*}{$\begin{array}{l}\text { Percentage of } \\
\text { estimate }\end{array}$} & \multicolumn{3}{|c|}{ No. of cases with under estimate } & \multicolumn{3}{|c|}{ No. of cases with over estimate } \\
\hline & USG & $\begin{array}{l}\text { Dare's } \\
\text { method }\end{array}$ & $\begin{array}{l}\text { Johnson's } \\
\text { method }\end{array}$ & USG & Dare's method & $\begin{array}{l}\text { Johnson's } \\
\text { method }\end{array}$ \\
\hline$<5$ & 19 & 7 & 15 & 12 & 13 & 10 \\
\hline $5-10$ & 8 & 6 & 2 & 16 & 13 & 10 \\
\hline$>10$ & 10 & 4 & 0 & 35 & 57 & 63 \\
\hline Total & 37 & 17 & 17 & 63 & 83 & 83 \\
\hline
\end{tabular}

The percentage of cases predicted within $10 \%$ of actual baby weight was $45 \%, 39 \%$ and $37 \%$ by USG, Dare's and Johnson's method respectively and were not significantly different (USG vs. Dare's: $\chi^{2}=0.74 ; \mathrm{p}=0.39$; USB vs. Johnson's: $=1.32 ; \mathrm{p}=0.25$; Dare's vs. Johnson's: $\left.\chi^{2}=0.34 ; \mathrm{p}=0.56\right)$.
All the three methods had higher estimates and the lower estimates were higher with USG while in the other two methods only $17 \%$ of the cases had underestimation (Table 4). The maximum higher prediction of baby weight was 46.7 per cent by USG, $58.1 \%$ with Dare's method and $70.5 \%$ with Johnson's method. 


\section{DISCUSSION}

Accurate estimates of fetal weight is necessary for antenatal monitoring and scheming effective and prospective management of labour and delivery in order to obviate perinatal morbidity and mortality. The mean weight + SD of the 100 babies monitored in the study was $2984+490.3$ grams, ranging from 2000 to 4500 gm per baby. Majority $(85 \%)$ of the babies were within the normal weight.

The results of the present study showed that the predicted fetal weight significantly correlated with the actual baby weight by all the three (USG, Dare's and Johnson's) methods. These methods could predict more than $60 \%$ of the cases correctly. The percentage of cases predicted within $10 \%$ of actual baby weight was $45 \%, 39 \%$ and $37 \%$ by USG, Dare's and Johnson's method respectively and were not significantly different which was comparable to that reported by Sherman and Bhandari. ${ }^{6,15}$ Correlation co-efficient with the actual baby weight was close in all the methods with the highest being Dare's method. Several studies have been done to find out the accurate method of estimating fetal weight. Dare and others reported that the percentage of error by Dare's method compared to actual baby weight was $20.1 \%$ while in the present study the error was relatively lower $(12.7 \%)$ with an absolute error of $379.0 \mathrm{gm} .{ }^{13}$ However, percentage error was least with USG which is just half of that of Dare's method and Johnson's method.

The absolute error of $190.8 \mathrm{gm}$ by USG in the present study is comparable to that reported by Tiwari and sood (198.6gm). ${ }^{5}$ The average maximum error was the least by USG $(1120 \mathrm{gm})$ in the present study though comparable with Dare's method (1172gm). These values are higher than that reported for Dare's clinical method (534.2gm) as well as USG method $(647.4 \mathrm{gm})$ as reported by Bhandari in their study. ${ }^{15}$ Though the predicted value by USG was closer to the actual baby weight, the present study showed least standard deviation of prediction error by Dare's method while Bhandari and others reported least for USG. ${ }^{15}$ As reported by Nayak and others the results of the study also showed that least average error was observed with USG while least standard error was observed with Dare's formula and the values were closer between USG and Dare's method. ${ }^{16}$ Comparison results showed that both USG and Dare's predictions are closer to the actual baby weight and hence Dare's method can be considered an alternative method in the absence of USG. The results corroborate with that the study of Nayak and others which reported that prediction of fetal weight by clinical method was as accurate as the ultrasonographic method. ${ }^{16}$ Majority of the studies including the present study reported USG was superior to clinical method in estimating fetal weight in terms of percentage error. ${ }^{1,17}$ On the other hand, a few studies showed that clinical method has the same accuracy or even better than USG. ${ }^{18-20}$ While reviewing clinical methods of foetal weight estimation, Ugwa concluded that though Dare's formula is a subjective method associated with notable predictive errors, in Nigeria it is the method still used in recent studies. ${ }^{21}$

Though Dare's method is limited to only singleton pregnancy, its advantage in the absence of facilities for USG cannot be ignored. In order to promote clinical based prediction of fetal weight, intensive training of the midwives and health staff at various health care facilities assumes significance. Post training assessment and periodical monitoring are important to ensure quality assured services and effective management of deliveries.

\section{CONCLUSION}

From the results of the present study, it can be concluded that Dare's method is superior to Johnson's method and equally good as USG in predicting the fetal weight. The minimal standard deviation of error with Dare's method makes it even better than USG. Also, Dare's method can be easily taught to the midwives and Compulsory Rotatory Residential Inters (CRRI) which makes it easy for them in estimating the fetal weight and taking decision regarding the mode of delivery and referral in case of macrosomia / IUGR which requires expert management. This clinical method is also a quick, effective and inexpensive technique in calculating the fetal weight even by less experienced person especially in areas of low resource setting.

\section{Funding: No funding sources}

Conflict of interest: None declared

Ethical approval: The study was approved by the Institutional Ethics Committee

\section{REFERENCES}

1. Chauhan SP, Hendrix NW, Magann EF, Morrison JC, Jenney SP, Devoe LD. Limitations of clinical and sonographic estimation of birth weight: experience with 1034 parturients. Obstet Gynecol. 1998;91:72-7.

2. Nzeh DA, Oyawoye O, Adetoro OO. Ultrasound estimation of birth weight in late pregnancy among African women. West African J Ultrasound. 2000;1:9-14.

3. Hanretty KP, Neilson JP, Fleming EE. Re-evaluation of clinical estimation of fetal weight: a comparison with ultrasound. J Obstet Gynaecol. 1990;10:199201.

4. Ong HC, Sen DK. Clinical estimation of fetal weight. Am J Obstet Gynecol. 1972;112(7):877-80.

5. Tiwari R, Sood M. Comparative study of various methods of fetal weight estimation at twin pregnancy. J Obstet Gynecol Ind 1989; 59:279-86.

6. Sherman DJ, Joseph SA, Tovbin J. A comparison of clinical and ultrasonic estimation of fetal weight. Obslet Gynecol. 1998;91:212-7.

7. Hendrix NW, Grady CS, Chauhan SP. Clinical versus sonographic estimates of birth weight in term 
of parturients. A randomized clinical trial. J Reprod Med. 2000;45:317-22.

8. Titapant V, Chawan PS, Mingnitpatanakul KA. Comparison of clinical and ultrasound estimation of fetal weight. J Med Assoc Thai. 2001;84:1251-7.

9. Barum JD, Gussman D, Wirth JC 3rd, Clinical and patient estimation of fetal weight vs ultrasound estimation. J Report Med. 2002;47:194-8.

10. Prechapanich J, Thitadilok W. Comparison of the Accuracy clinical and sonographic estimation of fetal weight. J Med Assoc Thai. 2004;87:S1-7.

11. Njoku C, Emechebe C, Odusolu P, Abeshi S, Chukwu C, Ekabua J. Determination of Accuracy of Fetal Weight Using Ultrasound and Clinical Fetal Weight Estimations in Calabar South, South Nigeria. Int Scholarly Res Notices, 2014. Available at: http://dx.doi.org/10.1155/2014/970973.

12. Gajendra ST, Tripathi A, Priyanka. Comparison of estimation of fetal weight by two clinical methods and ultrasound at term pregnancy. Int $\mathbf{J}$ Med Health Res. 2017;3(2):25-8.

13. Dare FO, Adernowore AS, Ifaturoti OO, Nganwuchu A. The value of symphysiofundal height / abdominal measurements in predicting fetal weight. Int $\mathrm{J}$ Gynecol Obslet. 1990;31:243-8.

14. Johnson RW, Toshach CE. Estimation of fetal weight using longitudinal mensuration. Am J Obstet Gynecol. 1954;68(3);891-6.

15. Bhandari AA, Pinto PJ, Shetty AP. Comparative study of various methods of fetal weight estimation at term pregnancy. J Obstet Gynecol Ind. 2004;54(4):336-9.
16. Nayak L, Pradhan, K, Kruthika M. Comparative study on Johnsons formula, Inslers formula and Hadlocks formula for estimating foetal weight at term. J Evid Med Health Care. 2017;4:600-5.

17. Kayem G, Grange GB, Goffinet F. Comparison of fundal height measurement and sonographically measured fetal abdominal circumference in the prediction of high and low birth weight at term. Ultrasound Obstet Gynecol. 2009;34:566-71.

18. Alnakash AH, Mandan DR. Fetal body weight: how far the clinical and sonographic estimations can coincide and their correlation with the actual birth weight. Iraqi J Comm Med. 2013;2:180-3.

19. Yazdani SH, Bouzari Z, Nazari AM. Comparison of fetal weight estimation with clinical, Ultrasonographic methods, and combined formula of Ultrasonography and maternal weight. Iranian $\mathbf{J}$ Obstet Gynecol Infertility. 2014;17(106):1-7.

20. Dudley NJ. A systematic review of the ultrasound estimation of fetal weight. Ultrasound Obstet Gynecol. 2005;25:80-9.

21. Ugwa EA. Advances in clinical estimation of foetal weight before delivery. Nigerian J Basic Clinic Sci. 2015;12:67-73.

Cite this article as: Parvathavarthini $\mathrm{K}$,

Santhanalakshmi C, Prasad G. Comparative study of various methods of fetal weight estimation at term pregnancy in a tertiary hospital in Kanchipuram, Tamil Nadu, India. Int J Reprod Contracept Obstet Gynecol 2018;7:1602-7. 